200. 黾谷哲治, 小笠原国郎, 小塚厚人：Streptonigrin 関連化合物の合成研究 (第 8 報*1) Ethyl 3-cyano-4-(3,4-dimethoxypheny1)-6-methyl-

2-quinoly1-5-pyridinecarboxylate の加水分解と Hofmann 反応化ついで2（複素環式化合物の合成研究 第199報*3)

Tetsuji Kametani, Kunio Ogasawara, and Atsuto Kozuka : Streptonigrin and Related Compounds. 妍.*1 Hydrolysis and Hofmann

Reaction of Ethyl 3-cyano-4-(3,4-dimethoxyphenyl)6-methy1-2-quinoly1-5-pyridinecarboxylate.*2

(Studies on the Syntheses of Heterocyclic Compounds. CXCIX**3).

(Pharmaceutical Institute, Tohoku University School of Medicine*4)

Attempts to convert the substituents in the pyridine ring of the compound (II), which was synthesized according to the procedure described in a preceding paper, into the same groups as the substituents in the pyridine ring (C) of streptonigrin (I) and its derivative (II) were investigated, and the cyano group of $\mathbb{I I}(\mathrm{R}=3,4$-dimethoxyphenyl-) could be converted into amino group successfully, but conversion of nitrile to the other groups resulted in failure. In this case, the cyano group extremely resisted to the hydrolysis to give an unusual abnormal product (XIX) under certain conditions or an unexpected compound (XVIII) through a removal of the cyano group. Furthermore, reduction of Ill with lithium aluminum hydride afforded the compound (XI) through a removal of the nitrile, unexpectedly. In the case of Hofmann reaction of the amide (XVII), the compound (XXI) expected was found to be formed together with an abnormal product (XXII), and catalytic hydrogenation of phenylurethan (XXVIII) of the alcohol (XXVI), which was obtained by reduction of the above compound (XXI), resulted in failure.

(Received March 7, 1967)

抗が性抗生物質 streptonigrin (I) 执よびその誘導体 (II) の合成を目的とし，種々の方法を検討してきた

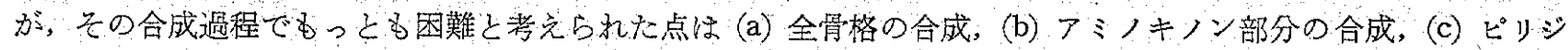
Chart 1 .

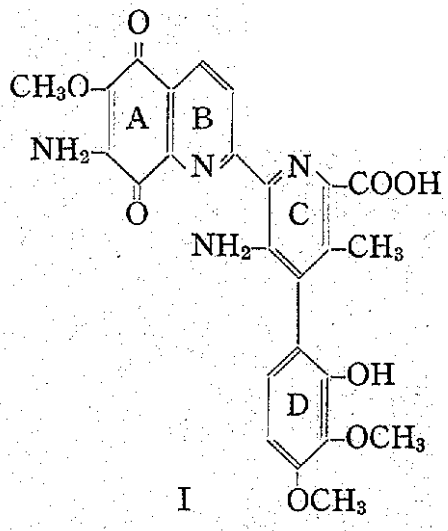

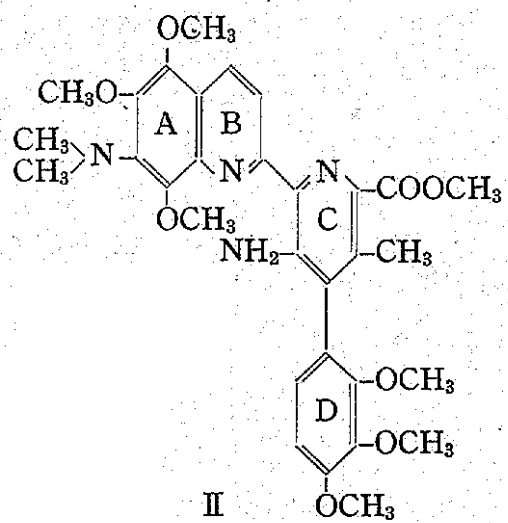

*1 第 7 報 : 本誌, 87, $1189(1967)$.

*2 日本薬学会東北支部 2 月例会 $(1967,2,18)$ 仙台化て発表.

*3 第 198 報： “本誌, 87, 1189 (1967).

*4 Kita-4-bancho, Sendai.

1) K. V. Rao, K. Biemann, R. B. Woodward: J. Am. Chem. Soc., 85, 2532 (1963). 
ン環 (C 環)への置換基の導入の3点である.これまでの研究2 7)で (a) 抽よび (b) に関してはある程度の成果 が得られているが，(c)汇関してはなだその目的を達していない，本報ではピリジン環への置換基導大の試みの 際得られた若干の知見について報告する.

Chart 2 .
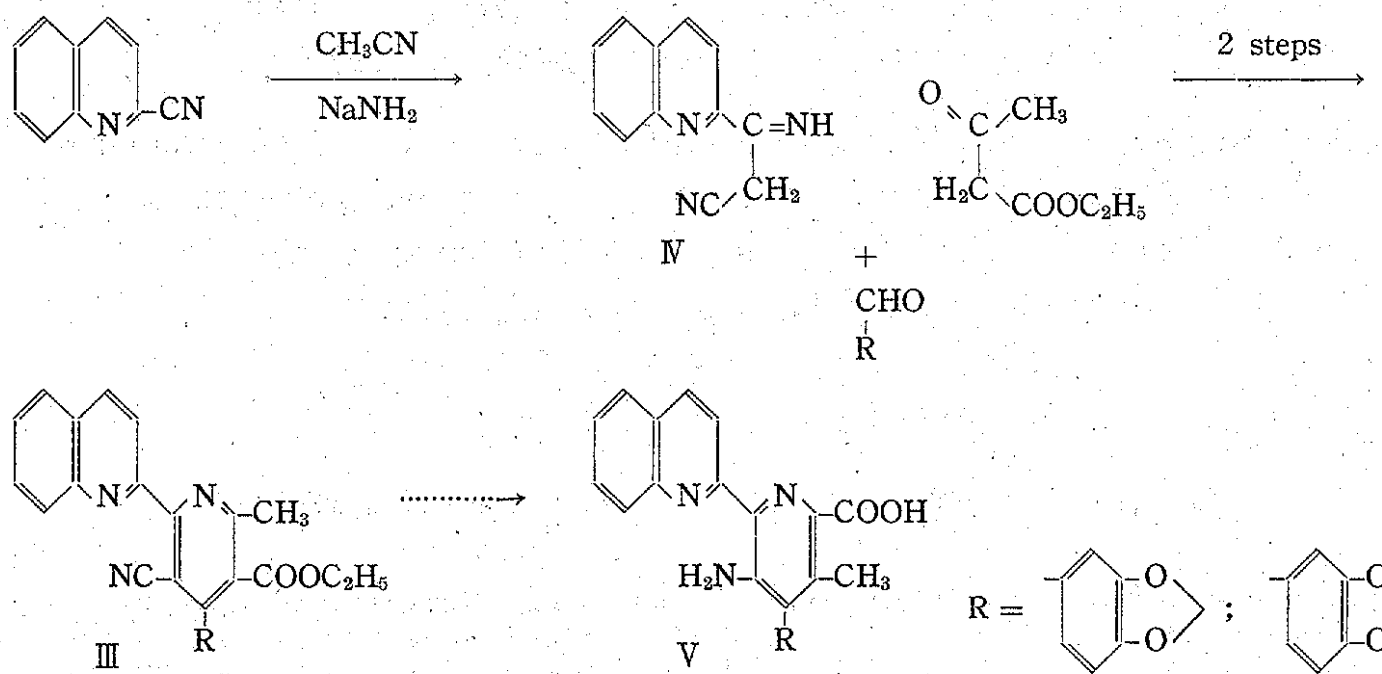<smiles>COc1ccccc1OC</smiles>

Chart 3 .<smiles></smiles>

VI<smiles>NC(O)c1ncccc1C(=O)O</smiles><smiles>[X]CCC(=O)c1cccnc1C(N)=O</smiles>

XI<smiles>COC(=O)c1ccc(C#N)nc1OC</smiles>

VII<smiles></smiles><smiles>CCOC(=O)CC(C)=O</smiles>

$+$<smiles>COc1ccc(C=O)c(OC)c1OC</smiles>

$\mathbb{X}$

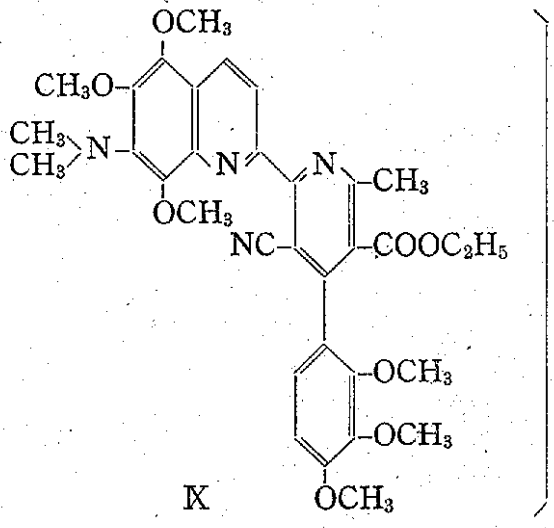

2)争谷, 小笠原 : 本誌, 85,985 (1965).

3) 龟谷，小笠原：本誌，86,55 (1966).

4)㿞谷, 小笠原, 塩 : 本誌, 86, 809 (1966).

5) 像谷, 小笠原，小塚：本誌，86，815(1966).

6) 亀谷，小笠原，小塚，塩：本誌，87，254(1967).

7) 黾谷, 小笠原, 小塚, 塩: 本誌, 87, 260 (1967). 
streptonigrin 骨格を有し，からその C 環に誘導し得る監換基学有する化合物 (III) 恃 Hantzsch 型合成法を応

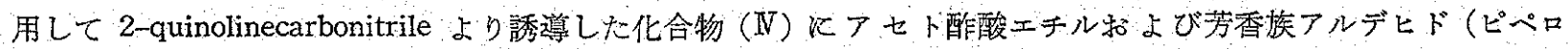
ナール扔よびベラトルムフルデとド) 起作用させて2 段階で合成している.5.

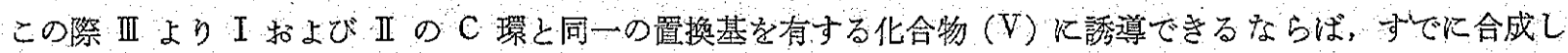

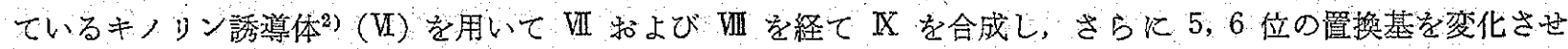

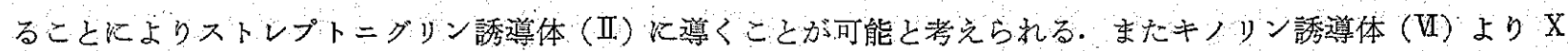
を経てアミノキノリン誘導体 (XI) を得ているので ${ }^{2}$ 上記と同様な方法でストレプトニグリン (I)の合成も可 能である考党られる。

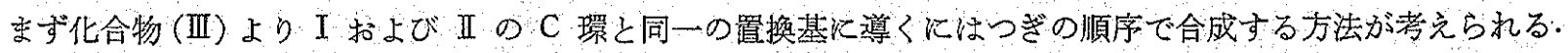
すなわち (1) シア）基を加水分解し，ついて Hofmann 反応によってアミノ基汇変換する；(2) エステル基を還 元してアルコール体となし，ついでメチル基に変换する：(3) $\alpha$ 位のメチル基を selenium oxide で酸化してカル ボキシル基湾換する 3 種の方法である。

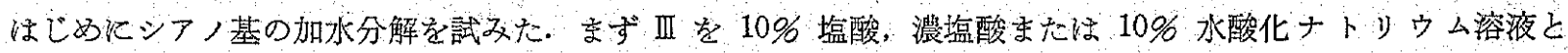

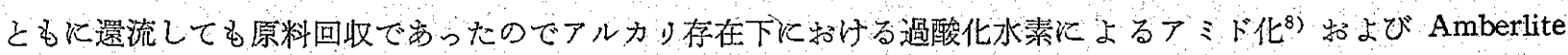

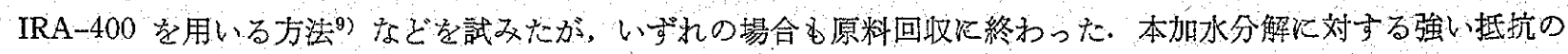

Chart 4.

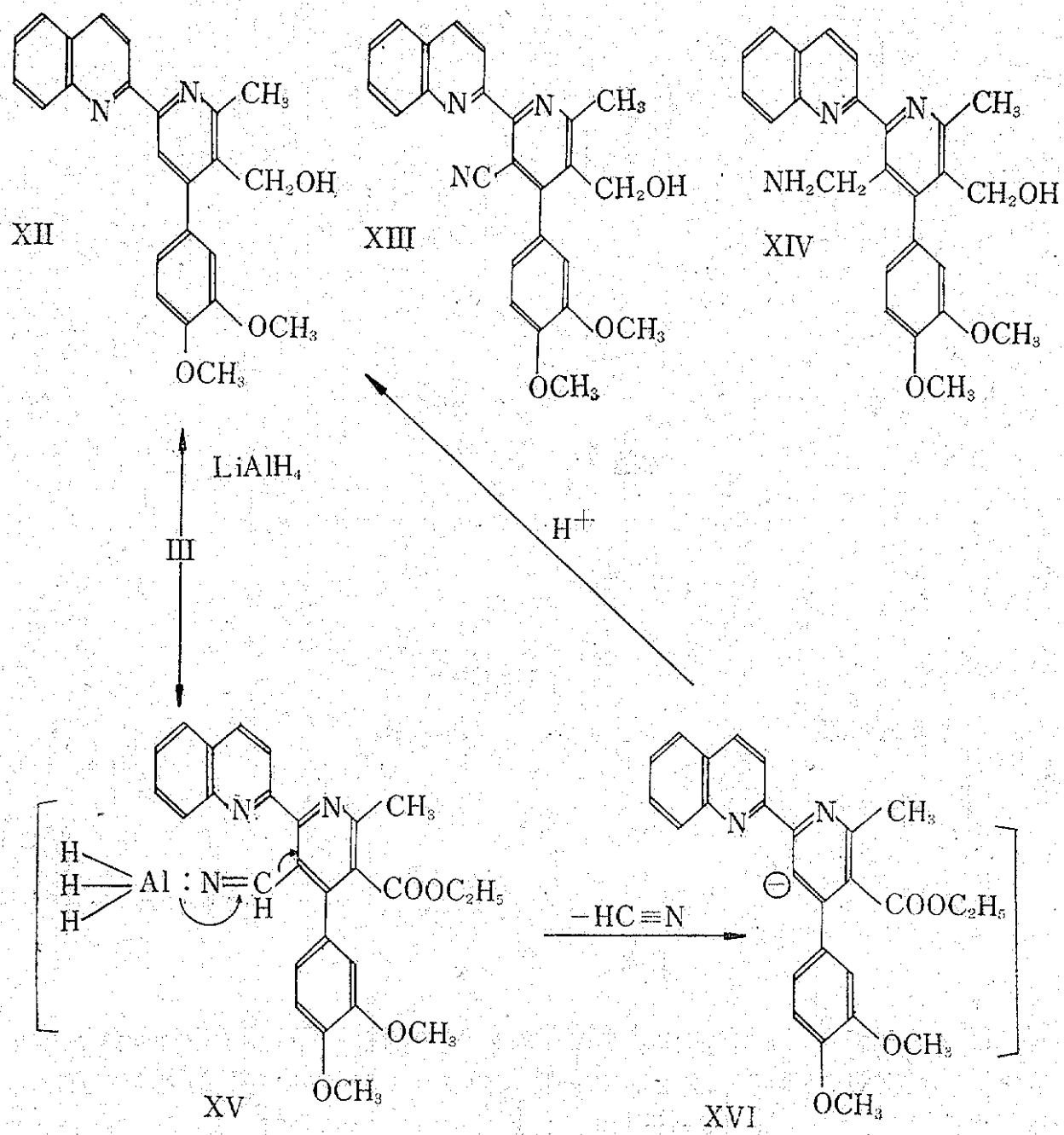

8) A. Georg, P. Bachmann: Helv, Chim. Acta, 26, 361 (1943).

9) A. Galat: J. Am. Chem. Soc., 70, 3945 (1948). 


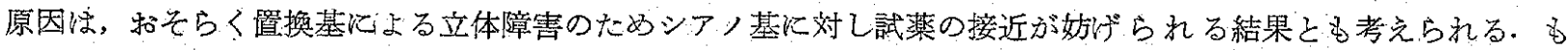
しこのよラにシアノ基に対して極端試薬の接近が妨げられているならば，亚を還元した場合エステル基のみが

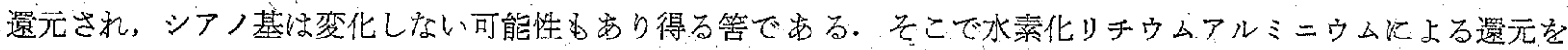
試みたところ予期しない化合物（XII）のみが得られ，期待されたXII 执よびXIV はまったく得られなかった。

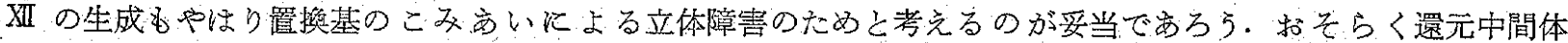

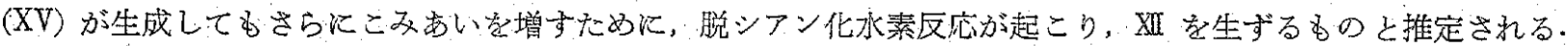

つぎに濃硫酸に上る加水分解を試反た：最初 III が温時濃硫酸に溶解後室温で1夜放置したのらアルニール中に 注加ずる方法を採用した。すなわちつルニール中に注ぐと黄色の硫酸塩を析出したが，本化合物は目的とするア

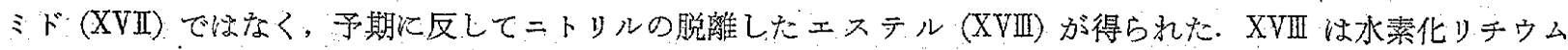

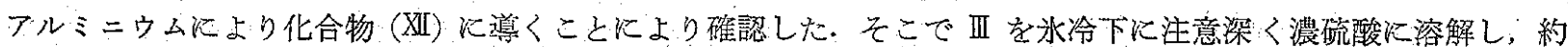

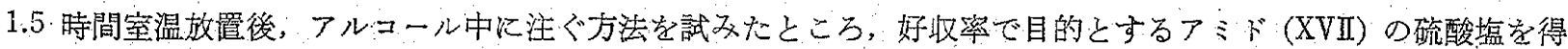
た. 本法は D 環が 3,4-dimethoxyphenyl，基の場合には好結果が得られたが，3,4-methylenedioxyphenyl 基の場 合㹥過クロル鉄反応陽性の精製不能の灰状物質とともに微量のタトン誘導体 (XIX) が得られたのみですった。こ のケトンKは異性体 $(\mathrm{XX})$ の可能性もあるが，NMR スペクトルに括いてベンゼン核プロトン (2H) がそれぞれ singlet として, キノリンの3，4 位のプロトン $(2 \mathrm{H})$ がそれぞれ doublet に認められることにより否定される. この化合物は Hoesch 反応類似の機棈を経て生成したるのと推定される.3,4-dimethoxyphenyl 基を有する場合 にはこの種のケ、トンの生成は認められなかった。

\section{Chart 5.}
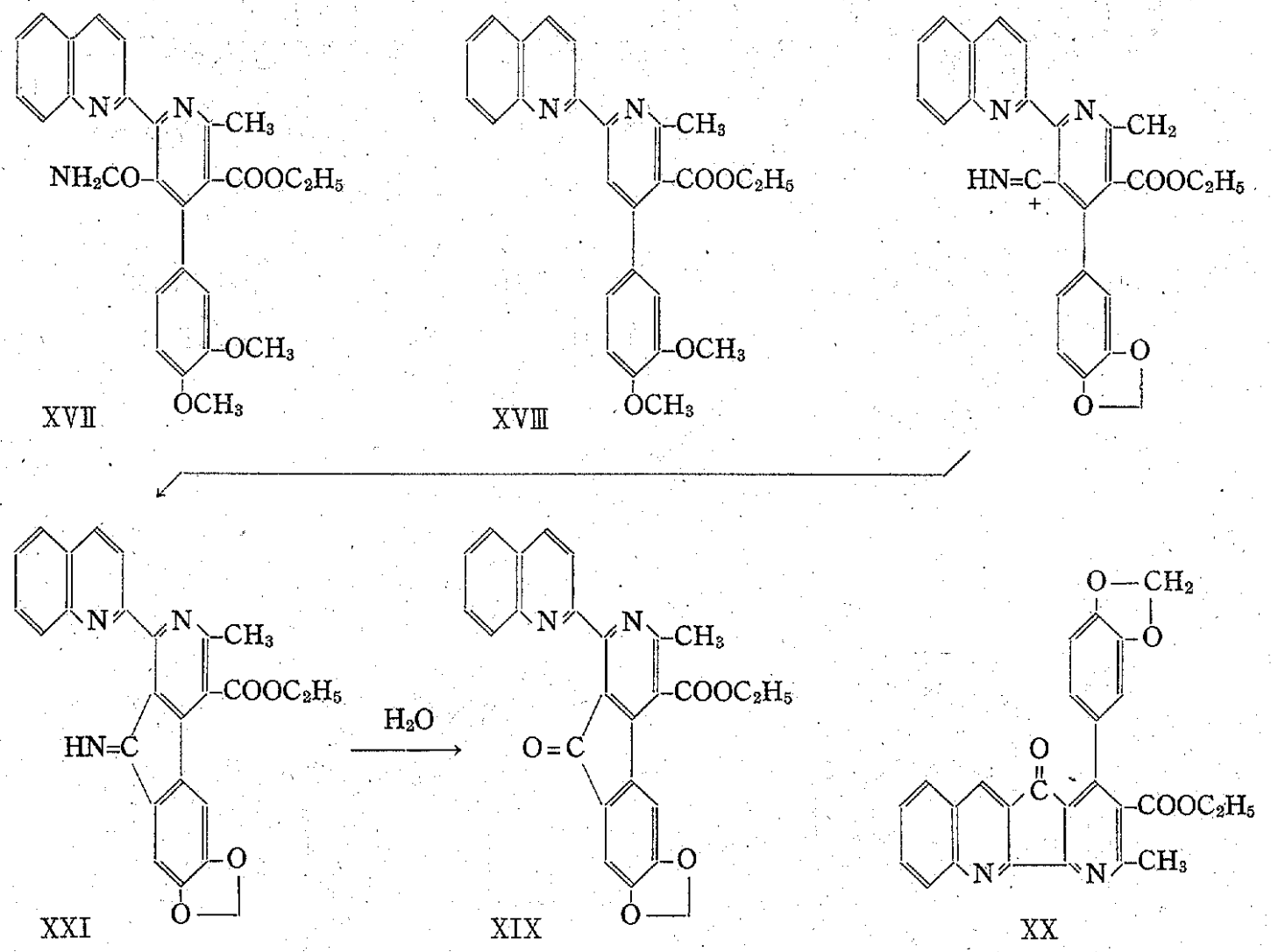

アミド (XVII) 得る方法が確立されたので，水酸化カリウム溶液中 XVII の Hofmann 反応を試みたとこる， 約 $40 \%$ の収率でアミン (XXI) が得られたが, この際, 微量の臭素付加体 (XXII) む得られた.この Hofmann 反応の收率索向上させるためにメタノール中ナトリウムメトキサイドの存在下に反応を試みたところ約 $80 \%$ の 收率でアミン (XXI)をメキルカルバメート誘導体 (XXII) として得ることができた。これを硫酸で加水分解して XXI に導いた. 
Chart 6.

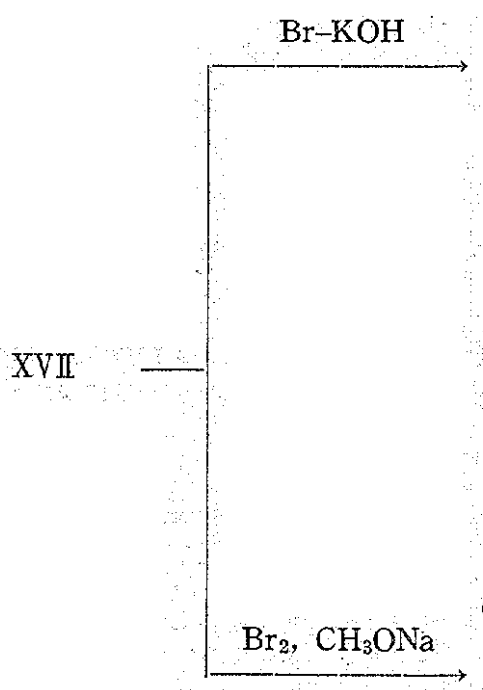<smiles>N#Cc1ccc2ccccc2n1</smiles><smiles></smiles><smiles></smiles>

$\mathrm{XXI}$

$\mathrm{OCH}_{3}$

$\mathrm{H}_{2} \mathrm{SO}_{4}$<smiles>CC(c1ccc2ccccc2n1)N(C)C</smiles><smiles>CCOC(=O)C1CCC(NC(OC)OC)C1</smiles>

$\times x$<smiles>C=Cc1ccc(OC)c(O)c1</smiles>

: $\mathrm{R}=\mathrm{H}$

XXIIa : $\mathrm{R}=\mathrm{Ac}$

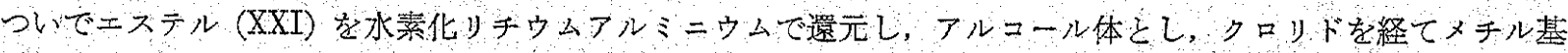

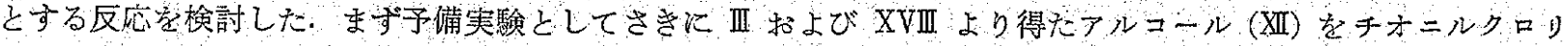

Chart 7.
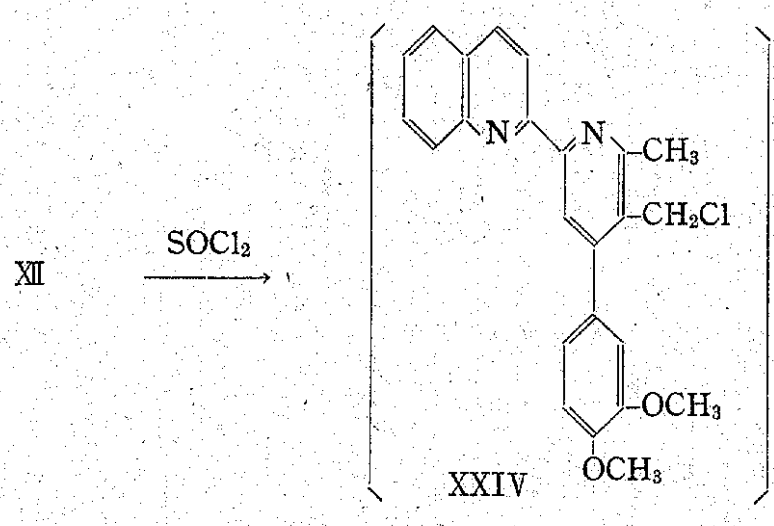

$\mathrm{LiAlH}_{4}$

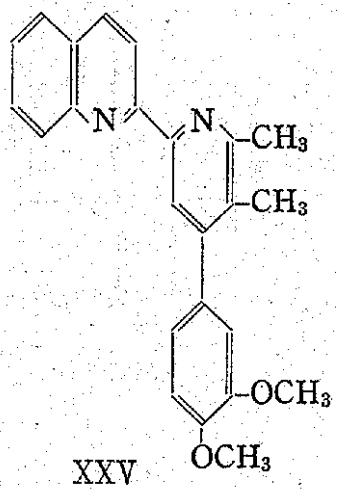

$\mathrm{XXI} \stackrel{\mathrm{LiAlH}_{4}}{\longrightarrow}$

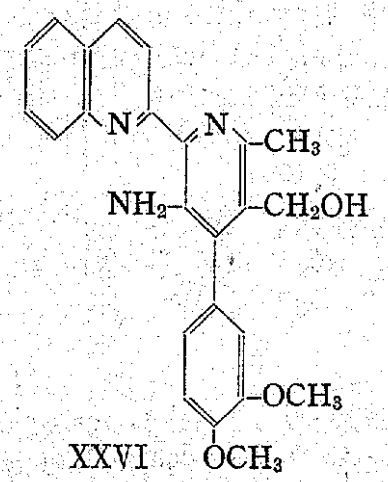


ドと処理しクロリド（XXIV）とし，これを単離することなくただちに水素化りチウムフルミニウムで睘元した ところメヂル誘導体 (XXV) を得ることに成功した。本法に準じてXXI についても同㮏な反応を試みたところ， 水素化リチウムアルミニウムによってアルニール体 (XXVI) を得たが，低取率ですった．牧えらく XXI がェー テル特よびテトラヒドロフランに難溶であるため加熱下に還元を試みたので，分解生成物が多いためと考它られ， る.ついで得られたアルコール体をチオニルクロリドと处理したが分解反応がおこり，クロリドは得られなかっ たので本法は断念した。

最後に pートルエンスルホニルクロリドによりXXVI をトシレートとし，これを還元してメチル基に導かんと したが，純粋なトシレートが得られなかったので，亀谷等间，の還元的メチル化を試みた。すなおちアルンール (XXVI) をフェニルイソシアナートと処理すると，2モルのフェニルイソジフナートと反応した化合物 (XXVII): そ1モルのブェニルイソシフナートと反応した化合物 (XXVII) が得られた。これらをパラジゥム炭による接触還

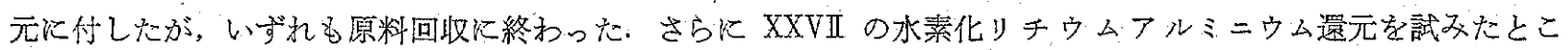
ろ，目的物が得られず，精製困難な物質とともにアミン(XXVI) が得られた。この事案はXXVII がベンジル位 で切断され難いことを示して拈り，またウレイド結合がアミノ基に变化したことはいったん $\mathrm{C}_{6} \mathrm{H}_{5} \mathrm{NHCH}_{2} \mathrm{NHC}_{6} \mathrm{H}_{5}$ 型汇還元され，これが容易们水分解されてアミノ基を生成したるのと考光られる.

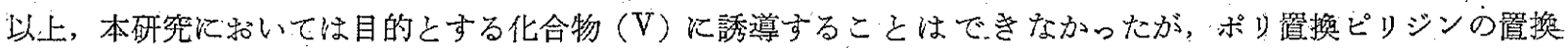
基の反応性について若干の興味ある事実を知ることがでさた。

Chart 8.

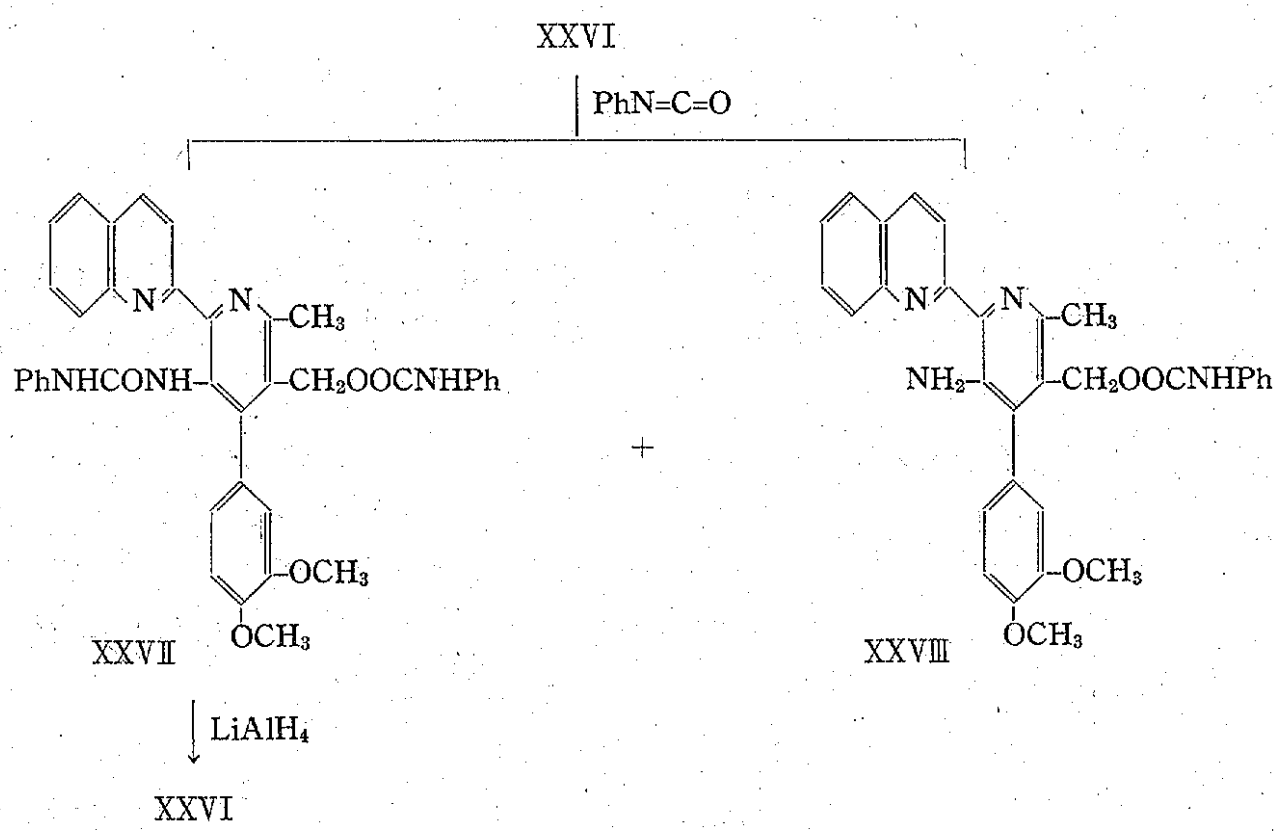

実 験 $の \quad$ 部”5

4-(3,4-Dimethoxyphenyl)-2-methyl-6-(2-quinolyl)-3-pyridinemethanol (XII) およびそのアセチル体ａ) Soxlet 抽出器中で III $2 \mathrm{~g}$., $\mathrm{LiAlH}_{4} 1 \mathrm{~g}$., 拉よび abs. ether $100 \mathrm{ml}$. 壳結晶が完全溶解するまで $4 \mathrm{hr}$. 還流後,

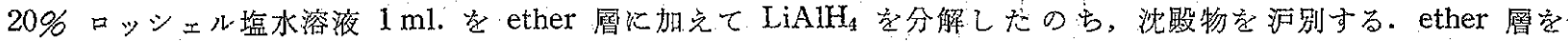

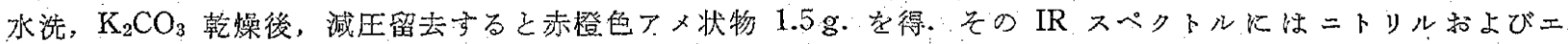
ステルによる昅取は多ら机ない. IR cm-1 $\left(\mathrm{CHCl}_{3}\right)$ ： ข

本物質は結晶化困難であるので， $\mathrm{Ac}_{2} \mathrm{O} 10 \mathrm{ml}$. と $3 \mathrm{hr}$. 畺流後, $\mathrm{Ac}_{2} \mathrm{O}$ を留去し, 残留物を $\mathrm{EtOH}$ で刺激する

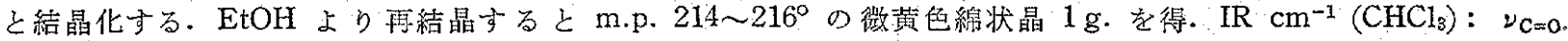
1735. $\mathrm{NMR}^{* 5}: 7.90\left(3 \mathrm{H}\right.$, singlet, $\left.\mathrm{CH}_{3}-\mathrm{CO}-\mathrm{O}-\right), 7.24$ (3H, singlet, $\left.2-\mathrm{CH}_{3}\right), 6.10\left(3 \mathrm{H}\right.$, singlet, $\left.-\mathrm{OCH}_{3}\right), 6.08$

*5 瀜点未補正.

*6 Varian A-60 を用い， $\mathrm{CDCl}_{3}$ 中 $\mathrm{Me}_{4} \mathrm{Si}$ を内部標準とし，タミカルシフトはて值で表わず。

10) T. Kametani, K. Fukumoto, Y Nomura: Chem. Pharm. Bull. (Tokyo), 6, 467 (1958). 
$\left(3 \mathrm{H}\right.$, singlet, $\left.-\mathrm{OCH}_{3}\right), 4.84\left(2 \mathrm{H}\right.$, singlet, $\left.-\mathrm{CH}_{2}-\mathrm{OH}\right), 3.01(3 \mathrm{H}$, singlet, 4-phenyl- 位 a aromatic protons $), 2.7 \sim$ $1.90(4 \mathrm{H}$, multiplet, quinoline $\omega$ benzene 核 protons), $1.70(1 \mathrm{H}$, doublet, quinoline $\beta-\mathrm{H}, \mathrm{AB}$ type $\mathrm{J}=8 \mathrm{c} . \mathrm{p} . \mathrm{s}$.$) ,$ 1.40 ( $1 \mathrm{H}$, doublet, quinoline $\gamma-\mathrm{H}, \mathrm{AB}$ type $\mathrm{J}=8 \mathrm{c}$.p.s.). $\mathrm{C}_{26} \mathrm{H}_{24} \mathrm{O}_{4} \mathrm{~N}_{2}$. Anal. Calcd. : C, $72.88 ; \mathrm{H}, 5.65 ; \mathrm{N}$, 6.54. Found : $\mathrm{C}, 73.21 ; \mathrm{H}, 5.67 ; \mathrm{N}, 6.87$.

b) XVII $0.8 \mathrm{~g}$. を abs. tetrahydrofuran $20 \mathrm{ml}$. 纪溶解させ，これを LiAlH $_{4} 0.8 \mathrm{~g} . の$ tetrahydrofuran (40 ml.)

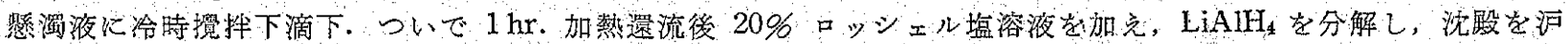
別. tetrahydrofuran 賸を $\mathrm{K}_{2} \mathrm{CO}_{3}$ 層を通して沪過後，減王留去すると赤褐色アメ状物を得. IR スヘクトルはa)

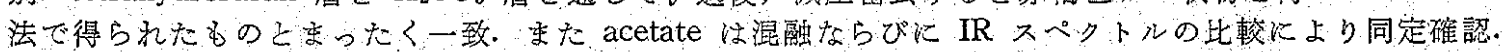

Ethyl 4-(3,4-dimethoxyphenyl)-2-methyl-6-(2-quinolyl)-3-pyridinecarboxylate (XVIII) II $1.2 \mathrm{~g}$. を conc. $\mathrm{H}_{2} \mathrm{SO}_{4} 3 \mathrm{ml}$. 飞愁渺させ，水溶上溶解するまで加温する，完全飞溶解後，室温て1夜放置し，EtOH $10 \mathrm{ml}$. を注ぐと黄色結晶が析出する。これを吸汇し，acetone-EtOHより再結晶すると黄色綿状晶 $1.4 \mathrm{~g}$. を得。m.p. 211 $\sim 212^{\circ} . \mathrm{C}_{26} \mathrm{H}_{24} \mathrm{O}_{4} \mathrm{~N}_{2} \cdot \mathrm{H}_{2} \mathrm{SO}_{4}$ Anal. Calcd. : C, $59.31 ; \mathrm{H}, 4.98 ; \mathrm{N}, 5.32$. Found: C, 59.67; H, 5.22; N,4.89.

前記 $\mathrm{H}_{2} \mathrm{SO}_{4}$ 塩を $5 \% \mathrm{NaHCO}_{3}$ 水溶液でてルカリ性として常法処理して得られる沈股を EtOH 上り再結晶し，

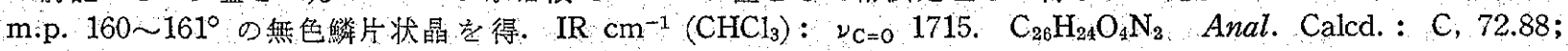
$\mathrm{H}, 5.65 ; \mathrm{N}, 6.54$. Found : $\mathrm{C}, 72.52 ; \mathrm{H}, 5.54 ; \mathrm{N}, 6.56$.

Ethyl 3-carbamoyl-4-(3,4-dimethoxyphenyl)-6-methyl-2-(2-quinolyl)-5-pyridinecarboxylate (XVII) III 9 g. を細末儿し，彾却下K conc. $\mathrm{H}_{2} \mathrm{SO}_{4} 20 \mathrm{ml}$. 火少量 に变化した反応混合物を EtOHを注ぐを，微黄色結晶が析出する．ether を加えさらに結晶の析出を促進させて

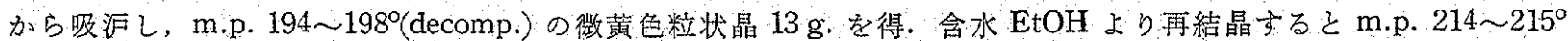
(decomp.) の黄色プリズム晶を得. $\mathrm{C}_{27} \mathrm{H}_{25} \mathrm{O}_{5} \mathrm{~N}_{3} \cdot \mathrm{H}_{2} \mathrm{SO}_{4} \cdot 1 \frac{1}{2} \mathrm{H}_{2} \mathrm{O}$ Anal. Calcd. : C, 54.37; H, 5.07; N, 7.04.

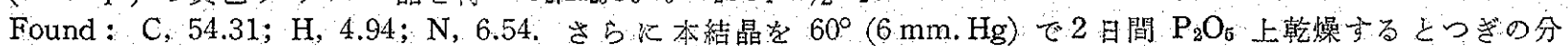
析值を与える. $\mathrm{C}_{27} \mathrm{H}_{25} \mathrm{O}_{5} \mathrm{~N}_{3} \cdot \mathrm{H}_{2} \mathrm{SO}_{4} \cdot \mathrm{H}_{2} \mathrm{O}$. Anal. Calcd. : C, 55.19; H, 4.97; N, 7.15. Found: C, 55.41; H, $4.78 ; N, 7.02$.

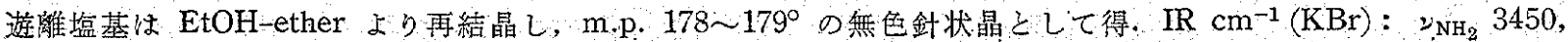
$3370,3190, \nu_{\mathrm{C}=0} 1725$ (ester). 1680 (amide). $\mathrm{C}_{27} \mathrm{H}_{25} \mathrm{O}_{5} \mathrm{~N}_{3}$ Anal. Calcd. : C, 68.78; H, 5.34; N, 8.91. Found: C, $68.88 ; \mathrm{H}, 5.52 ; \mathrm{N}, 9.17$.

Ethyl 3-methyl-6,7-methylenedioxy-9-0xo-1-(2-quinolyl)-9H-indeno[2,1-c]pyridine-4-carboxylate (XIX)

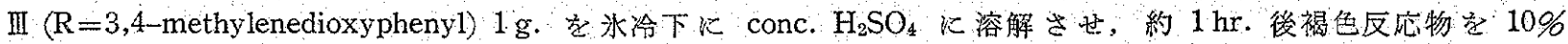
$\mathrm{Na}_{2} \mathrm{CO}_{3}$ 水溶液でアルカリ性とすると黑㷎色沈殿る析出。熱時 $\mathrm{CHCl}_{3}$ で抽出し，不溶物は沪別する。この不溶物 住 $\mathrm{FeCl}_{3}$ 反応陽性であるが精製不可能でおった。 $\mathrm{CHCl}_{3}$ 層は水洗, $\mathrm{Na}_{2} \mathrm{SO}_{4}$ 乾燥後, 減庄留去し，黑褐色?又状 残留物を $\mathrm{Al}_{2} \mathrm{O}_{3}$ カラムクロマトグラフィ一に付し， $\mathrm{CHCl}_{3}$ 留分より蕒色結晶 $30 \mathrm{mg}$.を得。 $\mathrm{CHCl}-\mathrm{EtOH}$ より 再結昆すると m.p. 255 256 の黄色針状晶老得. $\mathrm{FeCl}_{3}$ 反芯：陰性. IR cm ${ }^{-1}(\mathrm{KBr}): \nu_{\mathrm{C}=0} 1725$ (ester), $\nu_{\mathrm{C}=0}$ 1710 (ketone). NMR : 8.55 ( $3 \mathrm{H}$, triplet, $-\mathrm{OCH}_{2} \mathrm{CH}_{3}, \mathrm{~J}=7 \mathrm{c}$.p.s:), $7.30\left(3 \mathrm{H}\right.$, singlet, $\left.\mathrm{C}_{3}-\mathrm{CH}_{3}\right), 5.45$ (2H, quartet, $-\mathrm{OCH}_{2}-\mathrm{CH}_{3}, \mathrm{~J}=7 \mathrm{c}$.p.s.), 3.91 (2H, singlet, $\left.-\mathrm{O}-\mathrm{CH}_{2}-\mathrm{O}-\right), 2.96$ (1H, singlet, $\mathrm{C}_{5}-\mathrm{H}$ or $\left.\mathrm{C}_{8}-\mathrm{H}\right), 2.91$ (1H, singlet, $\mathrm{C}_{5}-\mathrm{H}$ or $\left.\mathrm{C}_{8}-\mathrm{H}\right), 2.6 \sim 2.0(4 \mathrm{H}$, multiplet, quinoline $\infty$ benzene 核 protons), 1.8 (1H, doublet, $\mathrm{AB}$ type, $\mathrm{J}=9$ c.p.s., quinoline $\beta-\mathrm{H}), 1.5(1 \mathrm{H}$, doublet, $\mathrm{AB}$ type, $\mathrm{J}=9 \mathrm{c}$.p.s., quinoline $\gamma-\mathrm{H}), \mathrm{C}_{26} \mathrm{H}_{18} \mathrm{O}_{5} \mathrm{~N}_{2}$ Anal. Calcd. : C, $71.22 ; \mathrm{H} 4.14 ; \mathrm{N}, 6.39$. Found : C, $71.57 ; \mathrm{H}, 4.40 ; \mathrm{N}, 6.16$.

Ethyl 3-amino-4-(3,4-dimethoxyphenyl)-6-methyl-2-(2-quinolyl)-5-pyridinecarboxylate (XXI) and ethyl 3-amino-6-bromomethyl-4-(3,4-dimethoxyphenyl)-2-(2-quinolyl)-5-pyridinecarboxylate (XXII) XVI-

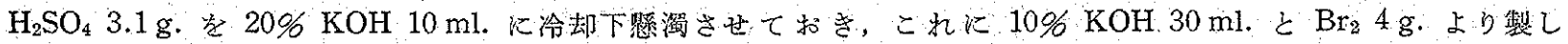

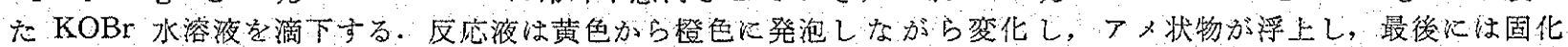

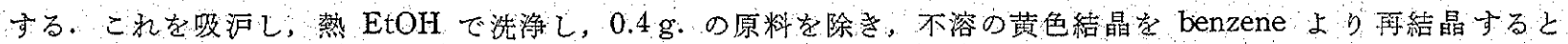

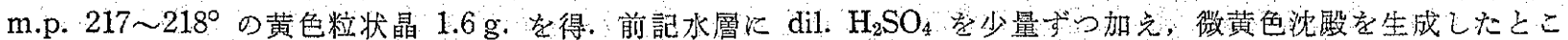

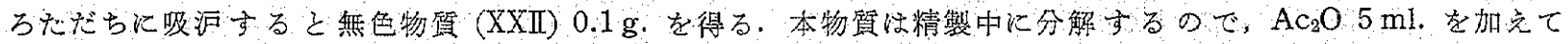

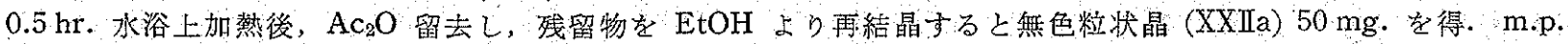
$178 \sim 179^{\circ}$ (decomp.). XXI : IR $\mathrm{cm}^{-1}(\mathrm{KBr}): \nu_{\mathrm{NH}_{2}} 3500,3350, \nu_{\mathrm{C}=\mathrm{o}} 1720$ (ester), $\delta_{\mathrm{NH}} 1620 . \mathrm{NMR}: 9.0$ (3H, triplet, $\mathrm{J}=7 \mathrm{c}$.p.s., $\mathrm{CH}_{3} \mathrm{CH}_{2} \mathrm{O}-, 7.43\left(3 \mathrm{H}\right.$, singlet, $\left.\mathrm{C}_{6}-\mathrm{CH}_{3}\right), 6.10\left(3 \mathrm{H}\right.$, singlet, $\left.\mathrm{OCH}_{3}\right), 6.13(3 \mathrm{H} \text {, singlet, OCH})_{3}$, 5.93 ( $2 \mathrm{H}$, quartet, $\mathrm{J}=7$ c.p.s., $\mathrm{CH}_{3} \mathrm{CH}_{2} \mathrm{O}-$ ), 3.07 ( $5 \mathrm{H}$, broad, $\mathrm{NH}_{2}$ and phenyl protons), $1.7 \sim 1.0$ (4H, multiplet, quinoline $\Phi$ benzene 核 protons), 1.80 ( $1 \mathrm{H}$, doublet, $\mathrm{AB}$ type, $\mathrm{J}=8 \mathrm{cp} . \mathrm{s}$, quinoline $\beta-\mathrm{H}), 1.20(1 \mathrm{H}$, doublet, $\mathrm{AB}$ type, $\mathrm{J}=8 \mathrm{c}$. p.s., quinoline $\gamma-\mathrm{H}) . \mathrm{C}_{26} \mathrm{H}_{25} \mathrm{O}_{4} \mathrm{~N}_{3} \quad$ Anal. Calcd. : $\mathrm{C}, 70.41 ; \mathrm{H}, 5.68 ; \mathrm{N}, 9.48$. Found: C, $70.47 ; \mathrm{H}, 5.55 ; \mathrm{N}, 9.43$.

$\mathrm{XXIl}: \mathrm{IR} \mathrm{cm}{ }^{-1}\left(\mathrm{CHCl}_{3}\right): \nu_{\mathrm{NH}} 3350, \nu_{\mathrm{C}=0} 1725$ (ester), $\nu_{\mathrm{C}=0} 1680$ (amide). NMR : 8.99 (3H, triplet, J=7 c.p.s., $\left.\mathrm{CH}_{3} \mathrm{CH}_{2}-\mathrm{O}\right), 7.6\left(3 \mathrm{H}\right.$, singlet, $\left.\mathrm{CH}_{3} \mathrm{CO}-\right)$ ) 6.20 (3H, singlet, OCH$), 6.15$ (3H, singlet, $\left.\mathrm{OCH}_{3}\right), 5.89(2 \mathrm{H}$, quartet, $\mathrm{J}=7$ c.p.s., $\left.\mathrm{CH}_{3} \mathrm{CH}_{2} \mathrm{O}-\right), 4.58\left(2 \mathrm{H}\right.$, singlet, $\left.-\mathrm{CH}_{2} \mathrm{Br}\right), 3.16$ ( $3 \mathrm{H}$, broad, aromatic protons), $2.8 \sim 2.0$ (quinoline protons). $\mathrm{C}_{28} \mathrm{H}_{26} \mathrm{O}_{5} \mathrm{~N}_{3} \mathrm{Br}$ Anal. Calcd. : C, 59.47; H, 4.64; N, 7.44. Found : C, 59.10; H, 4.85; N, 7.80 . 
Ethyl 3-methoxycarbamoyl-4-(3,4-dimethoxyphenyl)-6-methyl-2-(2-quinolyl)-5-pyridinecarboxylate

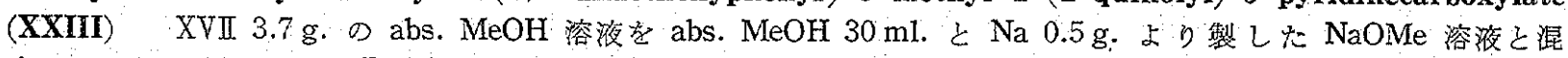

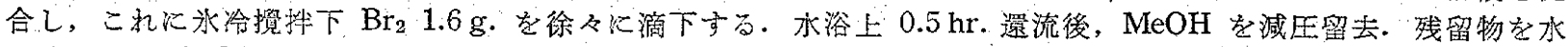

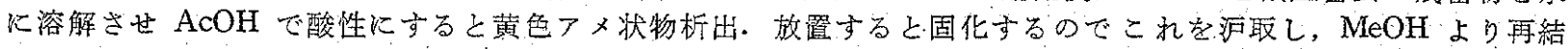
晶すると淡黄色 プリズム晶 3.5 g. を得. (ester). $\mathrm{C}_{28} \mathrm{H}_{27} \mathrm{O}_{6} \mathrm{~N}_{3}$ Anal. Calcd. : C, 67.05; H, 5.43; N, 8.38. Found : C, 67.04; H, 5.44; N, 8.42.

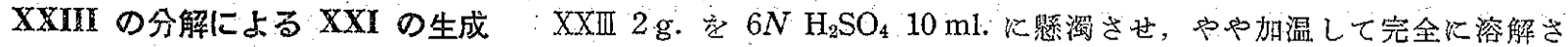

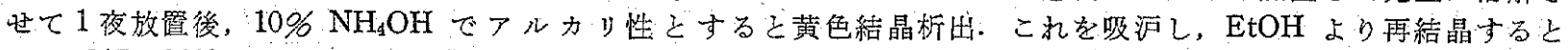
m.p. $217 \sim 218^{\circ}$ の黄色粒状晶 $1.6 \mathrm{~g}$.を得。混融, IR スペクトルの比較により別法で得た XXI と完全に一致す ることを確認した。

4-(3,4-Dimethoxyphenyl)-2,3-dimethyl-2-(2-quinolyl)pyridine (XXV) XII $0.7 \mathrm{~g} \cdot z$ dry benzene $10 \mathrm{ml} . \mathrm{K}$

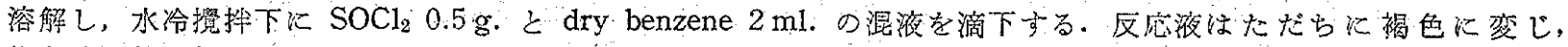

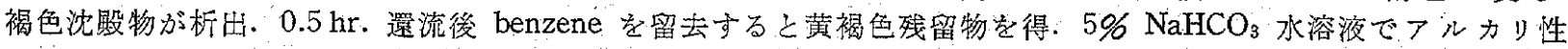

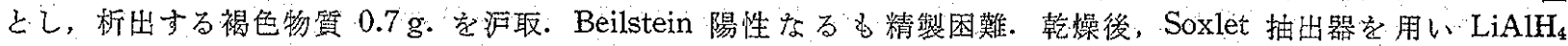

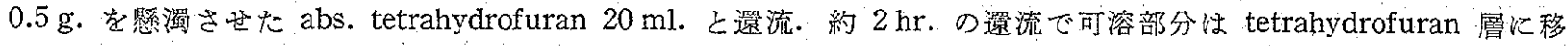
行し，反応液は赤橙色に変化した。この際不溶物 $0.5 \mathrm{~g}$. が残留した. tetrahydrofuran 層に $20 \%$ ロッシェル塩

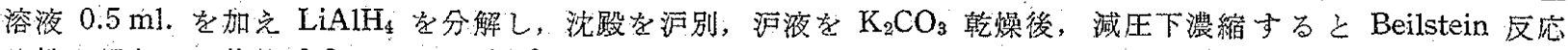

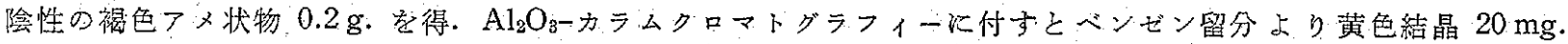
を得. EtOH 上り再結晶すると m.p. 195 1970 の黄色プリズム晶学得. IR スペクトルにはOHの吸收を認め ず. Beilstein 反応陰性. $\mathrm{C}_{24} \mathrm{H}_{22} \mathrm{O}_{2} \mathrm{~N}_{2}$ 'Anal. Calcd. : N, 7.56. Found: N, 7.82.

3-Amino-4-(3,4-dimethoxyphenyl)-6-methyl-2-(2-quinolyl)-5-pyridinemethanol (XXVI) XXI $0.8 \mathrm{~g}$.

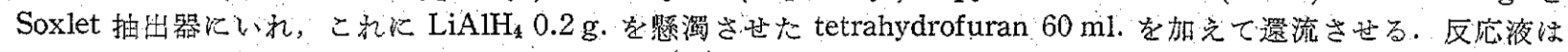
黄色より赤紫色に変化し，結晶が完全に溶解したのbさらに $30 \mathrm{~min}$. 逥流し，泠後 $20 \%$ ロッシニル塩水溶液

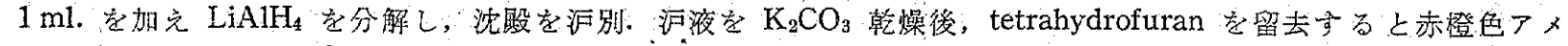

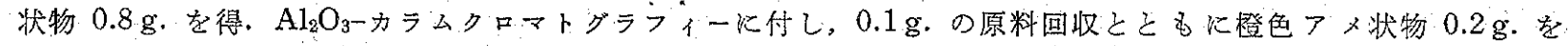

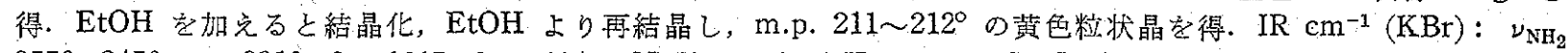
$3550,3450, \nu_{\mathrm{OH}} 3310, \delta_{\mathrm{NH}} 1615, \delta_{\mathrm{C}-\mathrm{o}} 1047 . \mathrm{NMR}: 7.33\left(3 \mathrm{H}\right.$, singlet, $\left.\mathrm{C}_{6}-\mathrm{CH}_{3}\right), 6.17$ (3H, singlet, $\left.\mathrm{OCH}_{3}\right), 6.09$ $\left(3 \mathrm{H}\right.$, singlet, $\left.\mathrm{OCH}_{3}\right), 5.60\left(2 \mathrm{H}\right.$, singlet, $\left.-\mathrm{CH}_{2} \mathrm{OH}\right), 3.92 \sim 3.88\left(6 \mathrm{H}\right.$, broad, benzene 核 protons, $\left.-\mathrm{NH}_{2},-\mathrm{CH}_{2} \mathrm{OH}\right)$, $2.8 \sim 2.0(4 \mathrm{H}$, multiplet, quinoline 核 benzene protons), $1.83(1 \mathrm{H}$, doublet, AB type J=9 c.p.s., quinoline $\beta-\mathrm{H}$ ), 1.03 ( $1 \mathrm{H}$, doublet, $\mathrm{AB}$ type $\mathrm{J}=9$ c.p.s., quinoline $\gamma-\mathrm{H}$ ). $\mathrm{C}_{24} \mathrm{H}_{23} \mathrm{O}_{3} \mathrm{~N}_{3}$. Anal. Calcd. : $\mathrm{C}, 71.80 ; \mathrm{H}, 5.78 ; \mathrm{N}$, 10.47. Found: $\mathrm{C}, 71.87 ; \mathrm{H}, 5.92 ; \mathrm{N}, 10.46$.

diacetate : 黄色粒状晶 ( $n$-hexane), m.p. 169 170。. IR cm $\mathrm{cm}^{-1}\left(\mathrm{CHCl}_{3}\right): \nu_{\mathrm{NH}} 3330, \nu_{\mathrm{C}=0} 1735$ (ester), $\nu_{\mathrm{C}=0}$ 1685 (amide). $\mathrm{C}_{28} \mathrm{H}_{27} \mathrm{O}_{5} \mathrm{~N}_{3}$ Anal. Calcd.: C, 69.26; H, 5.61. Found : C, 69.61; H, 5.87.

4-(3,4-Dimethoxyphenyl)-6-methyl-3-(3-phenylureido)-5-phenylcarbamoyloxymethyl-2-(2-quinolyl)pyridine (XXVII) and 3-Amino-4-(3,4-dimethoxyphenyl)-6-methyl-5-phenylcarbamoyloxymethyl-2-(2-quinolyl)pyridine (XXVIII) XXVI $0.2 \mathrm{~g}$. 艺 abs. benzene $4 \mathrm{ml}$. 《溶解し, こ机に $\mathrm{PhN}=\mathrm{C}=\mathrm{O} 0.12 \mathrm{~g}$. 老加え, 水浴 上加熱する. 約 $10 \mathrm{~min}$. で黄色結晶析出する. 約 $1 \mathrm{hr}$. 加熱後, ベンゼンを留去し，残留物に EtOH $10 \mathrm{ml}$.を 加光，析出する結晶を沪取し，得られた結晶を tetrahydrofuran-EtOH より再結晶すると m.p. 226.5 の。無色綿 状晶 $0.2 \mathrm{~g}$. 得. IR $\mathrm{cm}^{-1}\left(\mathrm{CHCl}_{3}\right)$ : $\nu_{\mathrm{NH}} 3310, \nu_{\mathrm{C}=0} 1730$ (ester), $\nu_{\mathrm{C}=0} 1680$ (amide). $\mathrm{C}_{38} \mathrm{H}_{33} \mathrm{O}_{5} \mathrm{~N}_{5}$ Anal. Calcd.: C, 71.34; H, 5.20; N, 10.95. Found: C, 71.22; H, 5.28; N, 11.19.

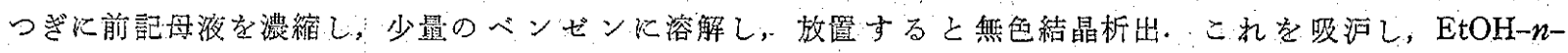
hexaneより再繥晶すると m.p. $232 \sim 233^{\circ}$ の然色粒状晶 $50 \mathrm{mg}$. 得. IR cm $\mathrm{cm}^{-1}\left(\mathrm{CHCl}_{3}\right): \nu_{\mathrm{NH}} 3400 \sim 3250, \nu_{\mathrm{C}=0}$ 1730 (ester). $\mathrm{C}_{31} \mathrm{H}_{28} \mathrm{O}_{4} \mathrm{~N}_{4}$ Anal. Calcd. : C, 71.52; H, 5.42; N, 10.76. Found : C, 71.79; H, 5.58; N, 10.67.

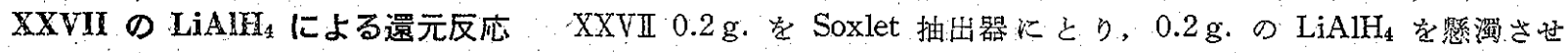

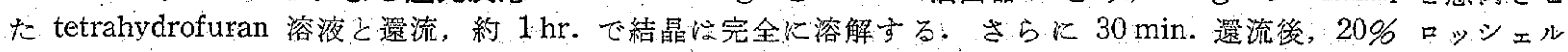

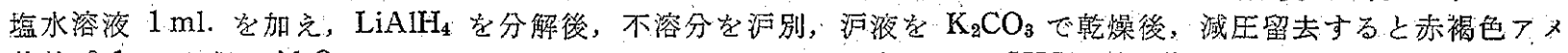

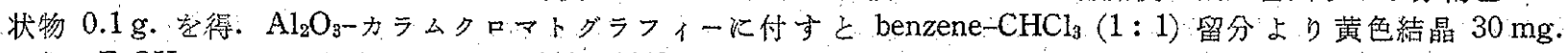
を得. EtOH 上り再結晶すると m.p. 110〜1120の黄色粒状晶を得. 本品はXXVI との混融によう融点降下を認 めず，からIR スペクトルも完全に一致した.

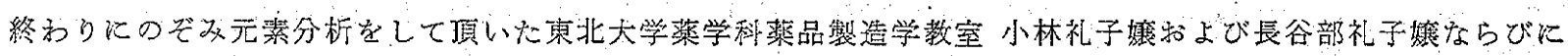
元䕀分析执よび NMRを測定して頂いた東北大学薬学科中央分析センターの皆様に深謝します。 